\title{
In Situ Alloying of a Modified Inconel 625 via Laser Powder Bed Fusion: Microstructure and Mechanical Properties
}

\author{
Giulio Marchese *(D), Margherita Beretta, Alberta Aversa $\mathbb{D}$ and Sara Biamino \\ Department of Applied Science and Technology, Politecnico di Torino, Corso Duca degli Abruzzi 24, 10129 Torino, \\ Italy; margherita.beretta@studenti.polito.it (M.B.); alberta.aversa@polito.it (A.A.); sara.biamino@polito.it (S.B.) \\ * Correspondence: giulio.marchese@polito.it; Tel.: +39-011-090-4763
}

Citation: Marchese, G.; Beretta, M. Aversa, A.; Biamino, S. In Situ Alloying of a Modified Inconel 625 via Laser Powder Bed Fusion: Microstructure and Mechanical Properties. Metals 2021, 11, 988 https://doi.org/10.3390/ met11060988

Academic Editor: Aleksander Lisiecki

Received: 28 May 2021

Accepted: 17 June 2021

Published: 21 June 2021

Publisher's Note: MDPI stays neutral with regard to jurisdictional claims in published maps and institutional affiliations.

Copyright: (c) 2021 by the authors. Licensee MDPI, Basel, Switzerland. This article is an open access article distributed under the terms and conditions of the Creative Commons Attribution (CC BY) license (https:/ / creativecommons.org/licenses/by/ $4.0 /)$.

\begin{abstract}
This study investigates the in situ alloying of a Ni-based superalloy processed by means of laser powder bed fusion (LPBF). For this purpose, Inconel 625 powder is mixed with 1 wt.\% of Ti6Al4V powder. The modified alloy is characterized by densification levels similar to the base alloy, with relative density superior to $99.8 \%$. The material exhibits Ti-rich segregations along the melt pool contours. Moreover, Ti tends to be entrapped in the interdendritic areas during solidification in the as-built state. After heat treatments, the modified Inconel 625 version presents greater hardness and tensile strengths than the base alloy in the same heat-treated conditions. For the solution annealed state, this is mainly attributed to the elimination of the segregations into the interdendritic structures, thus triggering solute strengthening. Finally, for the aged state, the further increment of mechanical properties can be attributed to a more intense formation of phases than the base alloy, due to elevated precipitation strengthening ability under heat treatments. It is interesting to note how slight chemical composition modification can directly develop new alloys by the LPBF process.
\end{abstract}

Keywords: additive manufacturing; laser powder bed fusion; Ni-based superalloys; Inconel 625; in situ alloying; alloy development

\section{Introduction}

Additive manufacturing (AM) processes have been rapidly growing due to the potential to create complex near-shape components through a layer-by-layer process [1-3]. In the last few years, many researchers focused their attention on the development and characterization of materials by AM technologies, which led to the optimization of the process parameters to reduce the presence of defects inside the components. In addition, many studies investigated the microstructure and mechanical properties of various metal alloys such as aluminum alloys, stainless steels, titanium alloys, nickel-based alloys, and composite materials [3-7]. This indicates the enormous interest in the development and characterization of alloys processed by AM techniques.

In proposing a strategy to develop new alloys tailored for AM, the current study focuses on the in situ alloying for the chemical modification of a Ni-based superalloy, commonly known as Inconel 625 (IN625), using the laser powder bed fusion (LPBF) process.

Among the Ni-based superalloys, IN625 is one of the most popular materials thanks to its intrinsic high oxidation and corrosion resistance in aggressive environments associated with good mechanical properties at elevated temperatures [8-11]. Moreover, this material exhibits high weldability, allowing the production of parts with low residual defects through LPBF [5,12]. The laser powder bed fused (LPBFed) IN625 alloy can exhibit mechanical properties compatible or superior to the traditional processed IN625 alloy after precise heat treatments $[13,14]$. The process parameters can tailor the crystallographic texture, thus involving the possibility to enhance the mechanical properties, as reported for LPBFed Inconel 718 alloy $[15,16]$.

Another strategy typically employed to tailor the mechanical properties of this material is the application of specific heat treatments, enabling the grains modification and 
phase formations $[13,14,17]$. In detail, recrystallization annealing and solution annealing treatments tend to induce recrystallization and grain growth, increasing the ductility. These heat treatments tend to homogenize the chemical composition, promoting a better distribution of strengthening phases during the subsequent aging treatment [14,18].

Another approach can be represented by the fabrication of metal matrix composites by the LPBF process. The addition of ceramic reinforcement can enhance the tensile properties of the material. For example, there are different studies on the development of metal matrix composites with ceramic reinforcements or carbon nanotubes utilizing the LPBF process [19-21].

Regarding the IN625, Chen et al. [22] created a composite IN625 with 4 wt.\% nano-TiC reinforcement, obtaining an increment of the tensile strengths correlated with a reduction of the ductility due to the combination of more mechanisms such as high dislocation density, Orowan strengthening, and grain refinements. Zhang et al. [23] created composites consisting of IN625 with $5 \mathrm{wt} . \%$ micrometric $\mathrm{TiB}_{2}$ particles, revealing a hardness increment. However, the densification level of the composites resulted in being inferior to the base alloy, with a relative density of $96.1 \%$. Wang et al. [21] reported that IN625 with $0.5 \mathrm{wt} . \%$ of carbon nanotube exhibited higher tensile strengths and lower ductility than the base alloy. All these studies imply a particular interest in enhancing the mechanical properties of IN625 alloy for possible industrial applications.

Starting from this consideration, the in situ alloying of IN625 by the addition of other metal powder to alter the chemical composition can represent an intriguing approach to strengthening the mechanical properties of the alloy. It should be noted that alternative alloys from IN625 alloy have already been proposed for the traditional processes, giving birth to the custom age 625 alloy and Inconel 725 alloys. These alloys underline the potential to produce a modified version of IN625 alloy. In particular, higher Ti content with respect to IN625 alloy leads to the activation of a more prominent formation of phases during aging treatments. These alloys are the perfect candidates for working in the oil and gas, marine, and chemical processing industries due to corrosive resistance similar to IN625 combined with superior tensile strengths [9,24-27]. The quantity of added Ti content must be carefully controlled, considering that a high Ti concentration can reduce the weldability of the alloy, thus promoting crack formations [28]. Several investigations currently underline the difficulty of processing crack-free Ni-based superalloys with a high quantity of $\gamma^{\prime}$-forming elements (e.g., Ti and Al) such as CM247LC and Inconel 738 [28-30].

Nevertheless, to the authors' knowledge, there are no studies on the in situ alloying of IN625 adding Ti-rich particles processed via the LPBF process in order to increase its precipitation strengthening ability under heat treatments. Higher content of Ti can promote more intense precipitation of $\gamma^{\prime \prime}$ phases as well as trigger the possible formation of the strengthening phase $\gamma^{\prime}$ phase under precise heat treatments [8,9].

The studies on in situ alloying are rapidly growing, as indicated by the recent investigations on this emerging field [31-34]. For instance, Vrancken et al. [33] created a modified Ti6Al4V alloy with $10 \mathrm{wt} . \%$ of Mo, increasing its tensile strength and ductility with respect to the base alloy by LPBF.

The current study aims to show the potential of the alloy development by means of the in situ alloying to create a modified IN625 alloy utilizing LPBF. In this work, the mixed powder was created by adding $1 \mathrm{wt} . \%$ of Ti6Al4V powder to IN625 powder and then processed by means of the LPBF process. The in situ alloying by the LPBF process resulted in a certain amount of residual segregations, avoiding a complete chemical homogenization. However, the preparation of tailored chemical compositions by gas atomization can be expensive, especially for a small batch of powder typically required for testing new chemical compositions. In contrast, in situ alloying can be faster and economical to design new alloys. In order to highlight the potential of this approach, the microstructure and mechanical properties of the modified IN625 were compared to the standard IN625, taking into account the presence of residual Ti-rich segregations. 


\section{Materials and Methods}

\subsection{Powder Preparation and Samples Manufacturing}

Gas atomized powders of IN625 and Ti6Al4V were supplied by EOS GmbH (Krailling, Munich, Germany). The IN625 and Ti6Al4V powders were sieved down to $50 \mu \mathrm{m}$ and $20 \mu \mathrm{m}$, respectively.

For the modified IN625 alloy, $99 \mathrm{wt} . \%$ of IN625 and $1 \mathrm{wt} . \%$ of Ti6Al4V were mixed using a ceramic jar in a ball milling system (without any grinding medium) with the application of a speed rate of $60 \mathrm{rpm}$ for $48 \mathrm{~h}$. In order to compare the mixed powder with standard IN625 alloy, the base alloy was also sieved down to $50 \mu \mathrm{m}$. The particle size distribution of the mixed powder presented a D50 of $25 \mu \mathrm{m}$ and a D90 of $46 \mu \mathrm{m}$.

Figure 1 displays the good distribution of the small Ti6Al4V particles with the IN625 particles. From now, the modified IN625 versions will be abbreviated as IN625mod.
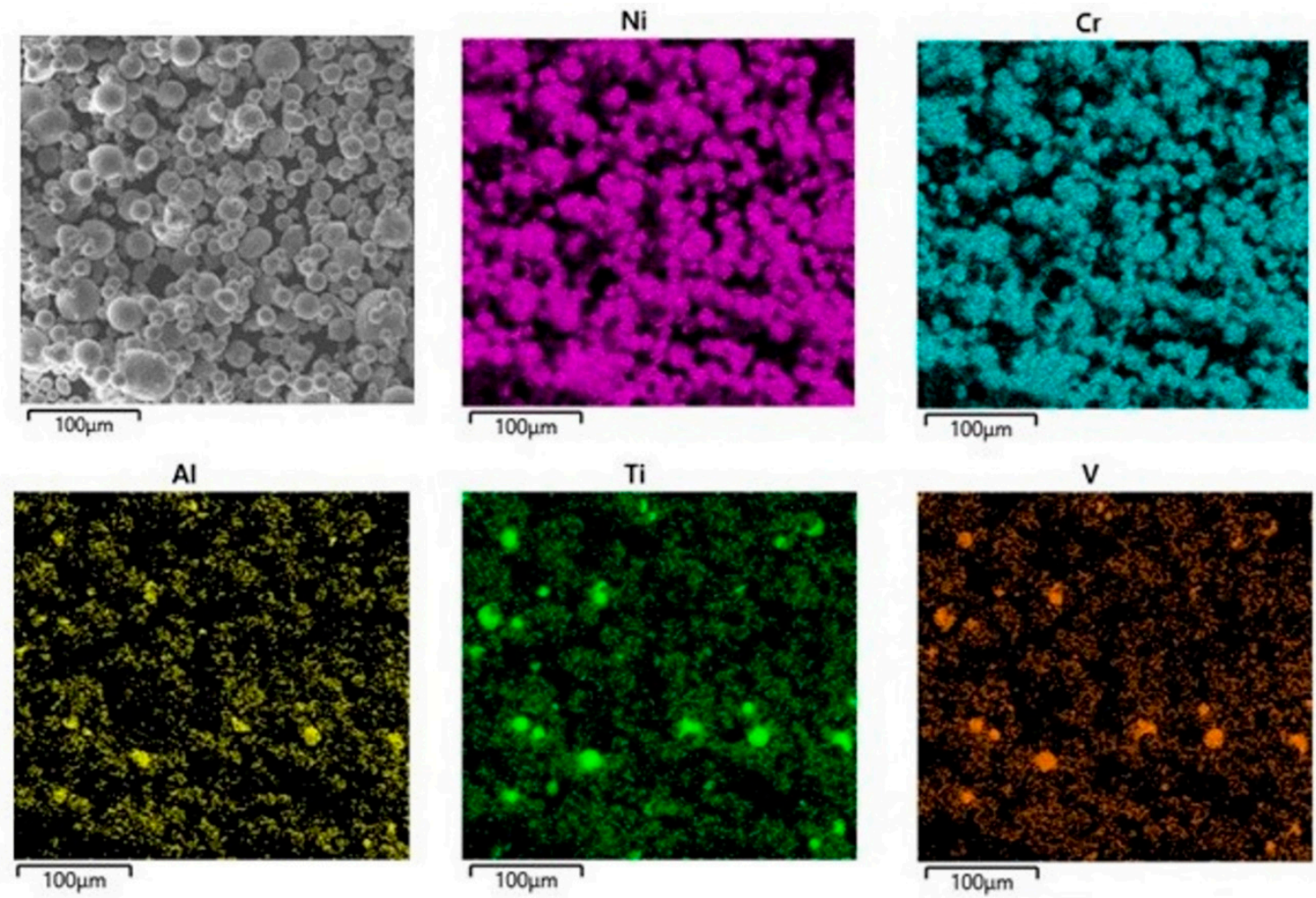

Figure 1. SEM image and EDS maps of the mixed powder composed of 99 wt.\% IN625 and 1 wt.\% Ti6Al4V.

A MLab Cusing R machine (Concept Laser GmbH, Lichtenfels, Germany) consisting of a fiber laser with a maximum power of $100 \mathrm{~W}$, and a laser spot of around $50 \mu \mathrm{m}$, was employed.

For the characterization, samples of $15 \times 15 \times 10 \mathrm{~mm}^{3}$ were built. The following process parameters were used: laser power of $95 \mathrm{~W}$, layer thickness at $20 \mu \mathrm{m}$, scanning speed of $1200 \mathrm{~mm} \mathrm{~s}^{-1}$, and hatching distance of $0.04 \mathrm{~mm}$. This set of process parameters was selected after a preliminary study conducted on different combinations of parameters. In particular, these parameters allowed good densification (relative density $>99.8 \%$ based on the optical image analysis) combined with an adequate production rate.

For all the samples, the same scanning strategy was employed: stripes of $5 \mathrm{~mm}$ with a rotation of $67^{\circ}$ between subsequent layers of powder.

\subsection{Heat Treatment Conditions}

A part of the IN625 and IN625mod samples underwent a solution annealing treatment at $1150{ }^{\circ} \mathrm{C}$ for $2 \mathrm{~h}$. This heat treatment is reported for IN625 alloy in the literature [35]. Moreover, some of the solution annealed samples were also subjected to aging treatment 
at $700{ }^{\circ} \mathrm{C}$ for $8 \mathrm{~h}$ to form strengthening phases. This temperature was selected based on the time-temperature-transformation diagram of IN625 alloy in order to promote the formation of the reinforcement $\gamma^{\prime \prime}$ phases $[8,9]$.

Hence, to sum up, the study on how the heat treatments impact the microstructure and the mechanical properties of the modified IN625 alloy was carried out through the characterization of three different conditions compared to the standard IN625 alloy:

- The as-built state is abbreviated as AB IN625 and AB IN625mod.

- The solution-treated state at $1150{ }^{\circ} \mathrm{C} / 2 \mathrm{~h}$ is indicated as ST IN625 and ST IN625mod.

- The solution-treated and aged state at $1150{ }^{\circ} \mathrm{C} / 2 \mathrm{~h}$ plus $700{ }^{\circ} \mathrm{C} / 8 \mathrm{~h}$ is reported as STA IN625 and STA IN625mod.

The solution annealing and aging steps were performed using a muffle furnace. After all the heat treatments, the samples were water quenched to avoid the precipitation of phases occurring at slow cooling rates.

\subsection{Microstructure Characterizations}

The residual porosity was evaluated by metallographic preparation ( $\mathrm{SiC}$ papers and then $1 \mu \mathrm{m}$ diamond suspensions) followed by means of a light optical microscope (LOMLeica DM 5000 M, Wetzlar, Germany) using a magnification of $100 \times$. Ten images were processed by means of ImageJ software for each set of parameters of the two alloys. It should be noted that the $z$-axis was considered for the study of the densification cutting in half the samples.

The microstructural characterization of samples was performed by means of LOM, scanning electron microscope (SEM-Phenom XL, Phenom-World, Eindhoven, The Netherlands), and a focused ion beam-scanning electron microscopy (FIB-SEM, TESCAN S9000G, Tescan Company, Brno, Czech Republic) equipped with energy-dispersive X-ray spectroscopy (EDS) detector. In order to reveal the microstructural characteristics of $\mathrm{AB}$, and heat-treated conditions, a mixed acid reagent $\left(15 \mathrm{~mL} \mathrm{HCl}, 10 \mathrm{~mL} \mathrm{CH}_{3} \mathrm{COOH}, 10 \mathrm{~mL} \mathrm{HNO}_{3}\right.$ ) was used. Moreover, the chemical etching allows highlighting the Ti-rich segregations. The image software was employed to determine the concentration and dimensions of the Ti-rich segregations at $200 \times$ by LOM images, using 20 images. Due to the reduced quantity of $\mathrm{Al}$ and $\mathrm{V}$ within Ti6Al4V, the description of the segregation will be chiefly referred to Ti, which is the predominant chemical element added to the Ni-based superalloy.

The influence of the heat treatments and the chemical modification on the lattice parameter of the austenitic phase of IN625 and IN625mod versions was determined using X-ray Diffraction analysis. A X'Pert (PANalytical, Almelo, The Netherlands) diffractometer was employed for this purpose with a $\mathrm{Cu} K_{\alpha}$ radiation using a Bragg-Brentano geometry (operating at $40 \mathrm{KV}$ and $40 \mathrm{~mA}$ ) with a step size of 0.013 and $25 \mathrm{~s}$ per step. The Nelson-Riley method was employed to obtain the lattice parameter of the austenitic matrix of the IN625 and IN625mod versions [36]. This method allows the extrapolation of the lattice parameter using more peaks, thus minimizing the error. In this case, the (111), (200), (220), (311), and (222) peaks of the austenitic phase were used [37].

Brinell hardness tests were carried out on the AB and heat-treated IN625 and IN625mod samples through an EMCO TEST M4U test machine (EMCO-TEST Prüfmaschinen GmbH, Kuchl, Austria), according to the ASTM E10-18 standard. Five indentations were performed on the surface of each sample (three samples for condition), applying a load of $62.5 \mathrm{~kg}$ for $15 \mathrm{~s}$ with a tungsten carbide indenter ball.

For the $\mathrm{AB}$ and heat-treated states of the two alloys, three tensile specimens were tested for each condition using a testing machine Z050 (Zwick Roell, Ulm, Germany). The samples were produced with the final shapes by means of LPBF, as provided in Figure A1 (Appendix A). The dimensions of the tensile specimens are: gauge length of $16 \mathrm{~mm}$, length of the reduced parallel section of $20 \mathrm{~mm}$, a diameter of $4 \mathrm{~mm}$, and a radius of fillets of $4 \mathrm{~mm}$. These dimensions are in agreement with the ASTM E8/E8M-21 standard. A strain rate of $0.128 \mathrm{~mm} \mathrm{~s}^{-1}$ was employed for the tensile test. 


\section{Results}

\subsection{Microstructure of the As-Built LPBF Conditions}

The as-built IN625 and IN625mod versions exhibited a similar level of densification (residual porosity inferior to $0.2 \%$ ), with the presence of small circular pores mainly up to around $10 \mu \mathrm{m}$ (Figure 2a,b). For the IN625mod (Figure $2 \mathrm{~b}$ ), grey spots are Ti-rich segregations, which can be already observed without chemical etching.
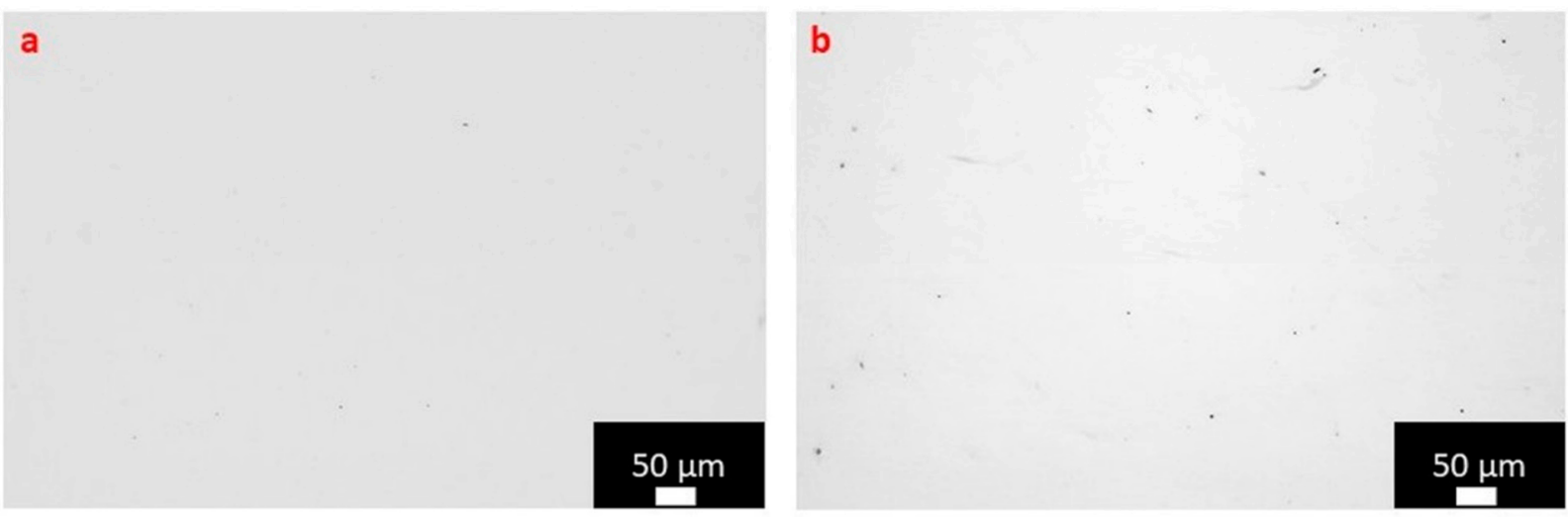

Figure 2. LOM images of the polished IN625 (a) and IN625mod (b).

The microstructure of the etched samples of IN625 and IN625mod are displayed in Figure 3. These micrographs underline the microstructure of AB IN625 state (Figure 3a,b) and the microstructure of the AB IN625mod state with residual segregations indicated by red arrows (Figure $3 \mathrm{c}, \mathrm{d}$ ). These Ti-rich segregations tend to be located along the melt pool contours, as clearly displayed in the EDS maps reported in Figure 3e.

The dimensions of the segregations tend to be mainly around $10-20 \mu \mathrm{m}$, and the amount of the segregations calculated by LOM analysis determined values around $0.30 \pm 0.09 \%$. A representation of the approach used with ImageJ to estimate the degree of segregations is provided in Figure A2 (Appendix A). Additionally, considering the grains along the building direction ( $z$-axis), the addition of Ti-rich particles did not provoke remarkable modification to the grains that remain columnar as the base alloy.

For IN625 and IN625mod states, the AB material presented melt pools generated by the LPBF process with fine networking of dendritic structures (Figure 4a-d). SEM images of one melt pool contour of the two materials (Figure $4 \mathrm{~b}, \mathrm{~d}$ ) pointed out the fine dendritic/cellular networking of both the conditions having PDAS around $0.30 \mu \mathrm{m}$, indicating that the addition of Ti did not alter the dimensions of the dendritic structures.

For IN625mod, performing semi-quantitative EDS analysis in different areas, the analysis pointed out a concentration of Ti around $1.5 \mathrm{wt} . \%$ against a concentration of $0.4 \mathrm{wt} . \%$ for the base alloy (Table 1). From the EDS analyses, it is confirmed that the addition of $1 \mathrm{wt} . \%$ of Ti6Al4V significantly affects only the value of Ti. The chemical composition evaluated for the IN625 alloy is within the chemical composition described in the UNS N06625.

Table 1. EDS analyses of the IN625 and IN625mod alloys (chemical elements in wt.\%) compared to the main chemical elements of the IN625 (UNS N06625).

\begin{tabular}{ccccccccccc}
\hline & $\mathbf{N i}$ & $\mathbf{C r}$ & $\mathbf{M o}$ & $\mathbf{F e}$ & $\mathbf{N b}$ & $\mathbf{C o}$ & $\mathrm{Si}$ & $\mathrm{Ti}$ & $\mathrm{Al}$ & $\mathbf{V}$ \\
\hline IN625 & 64.2 & 20.9 & 9.0 & 0.8 & 4.1 & 0.1 & 0.1 & 0.4 & 0.4 & - \\
\hline IN625mod & 63.3 & 20.9 & 8.8 & 0.7 & 4.0 & 0.2 & 0.1 & 1.5 & 0.4 & 0.1 \\
\hline $\begin{array}{c}\text { UNS } \\
\text { N06625 }\end{array}$ & $\mathbf{2} 58.0$ & \multirow{2}{*}{$20-23$} & $8-10$ & $\leq 5$ & \multirow{2}{*}{$3.15-4.15$} & $\leq 1.0$ & $\leq 0.5$ & $\leq 0.4$ & $\leq 0.4$ & - \\
\hline
\end{tabular}



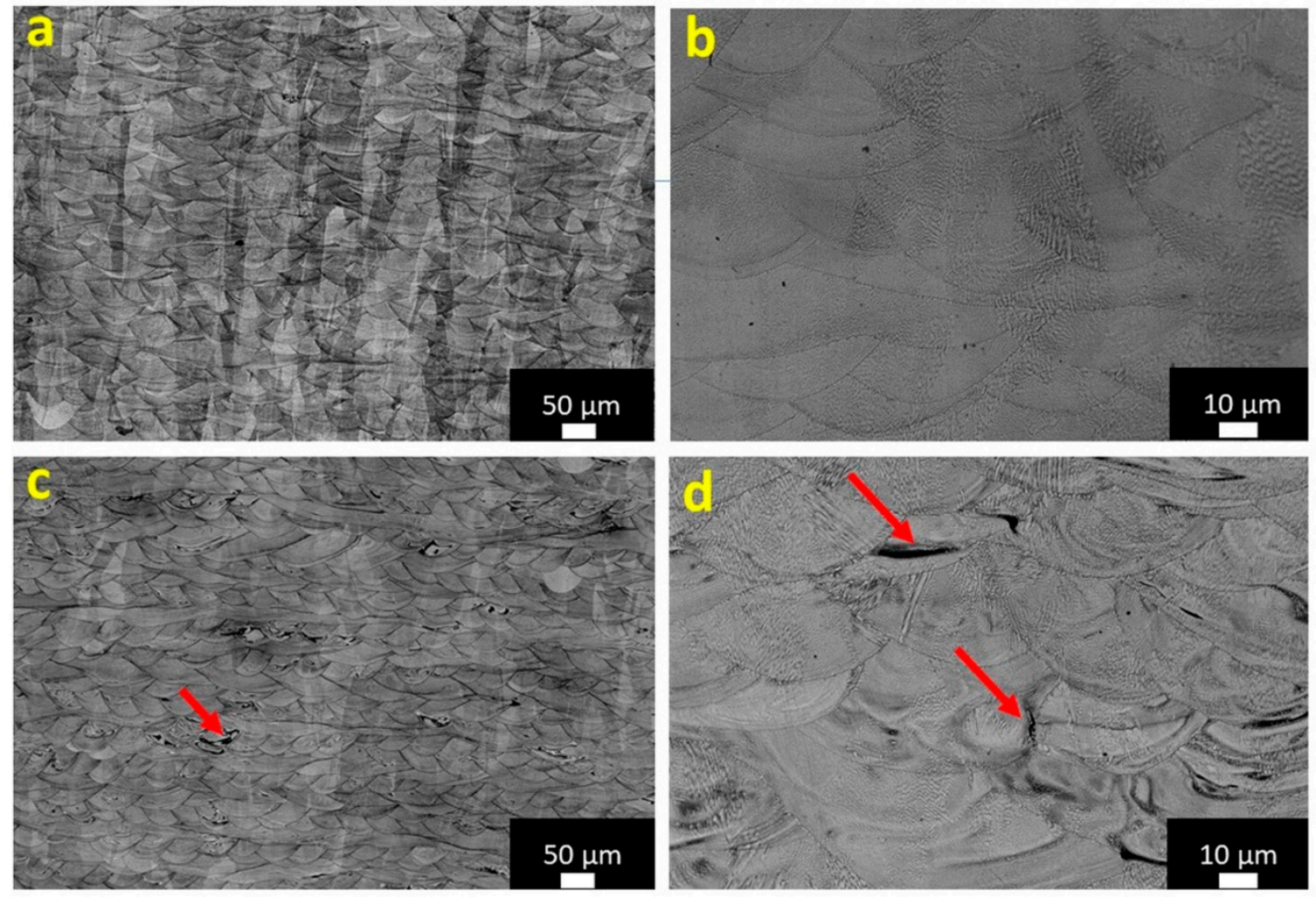

e
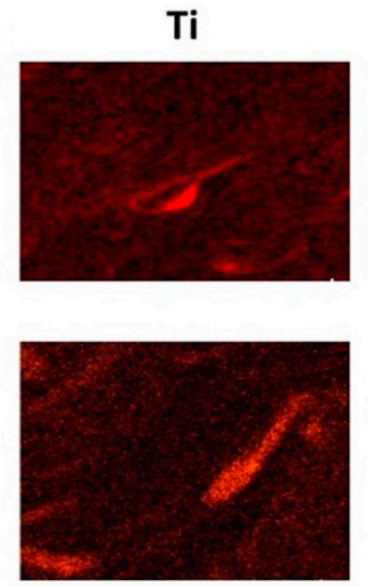

$\mathrm{Ni}$
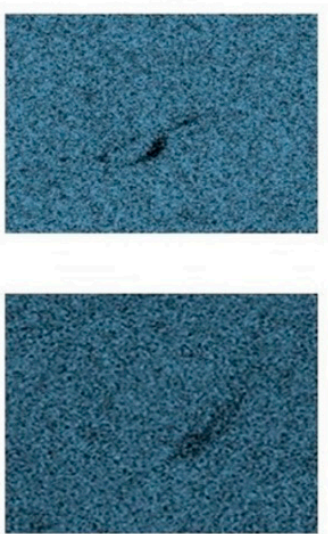
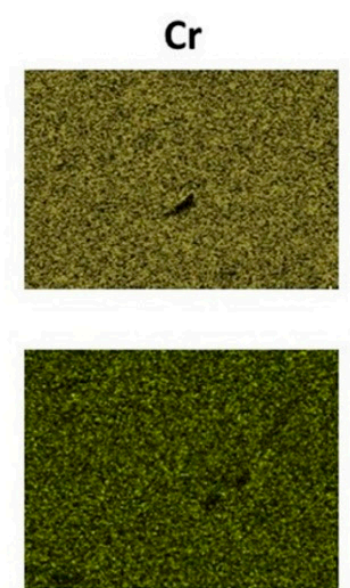
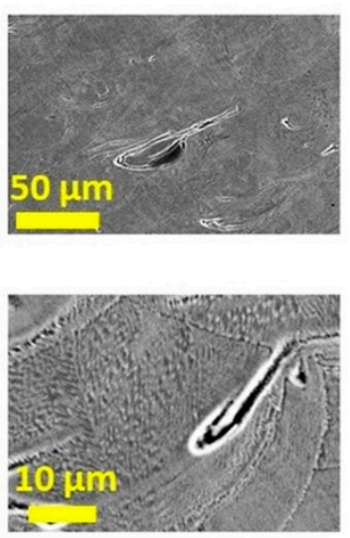

Figure 3. LOM images of the AB IN625 (a,b) and AB IN625mod (c,d). Presence of residual Ti-rich segregations (indicated by the red arrows) in the AB IN625mod version. EDS maps of the AB IN625mod (e) revealing the zones with Ti-rich segregations along the melt pool contours.

\subsection{Microstructural Evolution}

The LOM images of the ST IN625, STA IN625, ST IN625mod, and STA IN625mod are shown in Figure 5a-d, respectively. The high temperature of the solution annealing promotes the recrystallization, grain growth, and formation of twin annealing boundaries for IN625 (Figure 5a) and IN625mod (Figure 5c). The application of an aging treatment at $700{ }^{\circ} \mathrm{C}$ for $8 \mathrm{~h}$ induces the formation of precipitates, mainly along the grain boundaries, as displayed in the optical micrographs of IN625 (Figure 5b) and IN625mod (Figure 5d). 

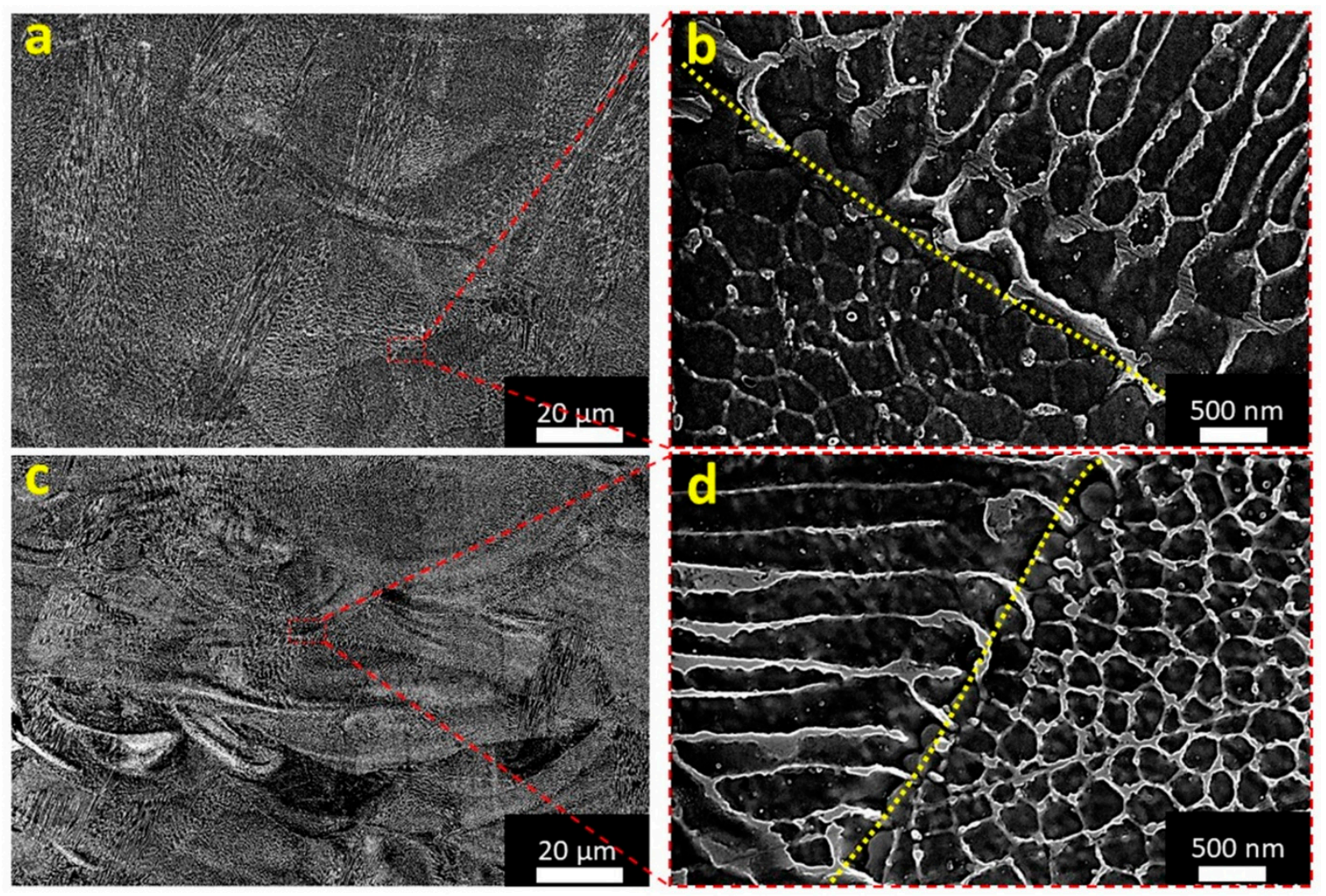

Figure 4. SEM images of the AB IN625 (a,b) and AB IN625mod (c,d), showing the fine dendritic structures. The yellow line indicated the melt pool contours for the high magnification images.

For the IN625mod version, it is still possible to observe segregations, which exhibited circular shapes. The Ti-rich segregations appeared to promote clustering of precipitates (as indicated by red arrows in Figure $5 c, d$ ). Considering the ST state, the precipitates can be mostly like MC carbides due to the high content of Ti, while in the STA state, the thermal exposures can promote the formation of $\gamma^{\prime}$ and $\gamma^{\prime \prime}$ phases. For a similar temperature, it is reported that MC carbides enriched in Ti can be formed [8,38].

EDS maps on the STA IN625mod alloy (Figure 5e) revealed that Ti was homogenously distributed except in some areas with Ti-rich segregations.

The segregation presented an average size of $20 \mu \mathrm{m}$, in line with the $\mathrm{AB}$ condition. Additionally, the segregation concentration was similar to the AB IN625mod with a value of $0.29 \pm 0.12 \%$. It is, therefore, evident that the large segregations were not dissolved by the heat treatment.

SEM images show the very fine sub-micrometric carbides of the ST IN625 alloy (Figure 6a,b). Likewise, the ST IN625mod version presented the same microstructure with larger precipitates close to the segregation areas (Figure $6 c, d$ ). From a statistical analysis, the carbides of the ST IN625 and ST IN625mod states had dimensions around $50 \pm 30 \mathrm{~nm}$. However, the ST IN625mod presented carbides with large dimensions around $300 \pm 100 \mathrm{~nm}$, close to the Ti-rich segregate areas. 


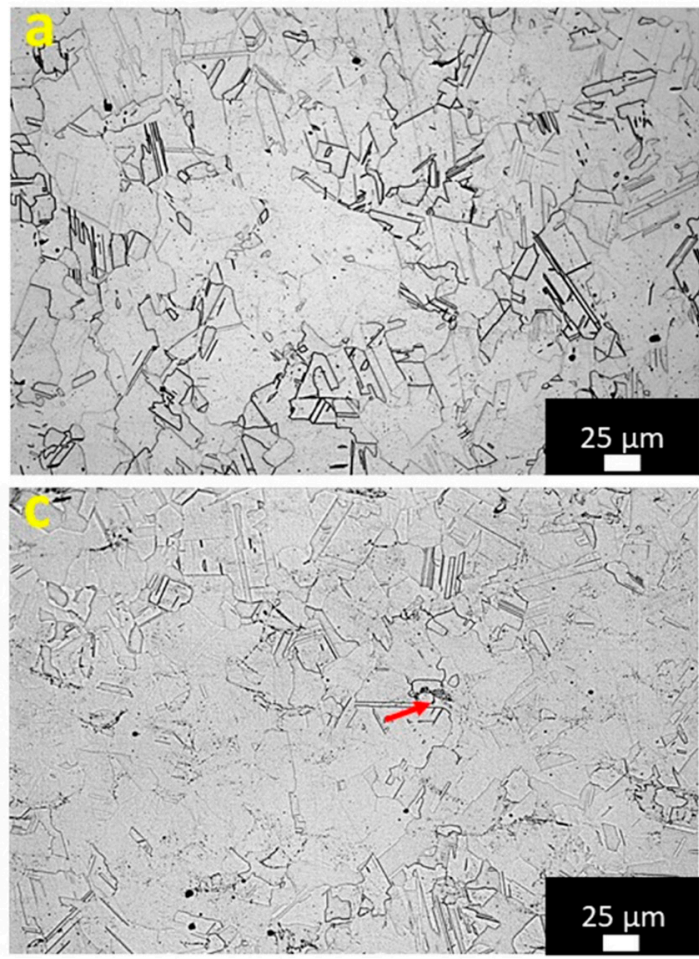

e
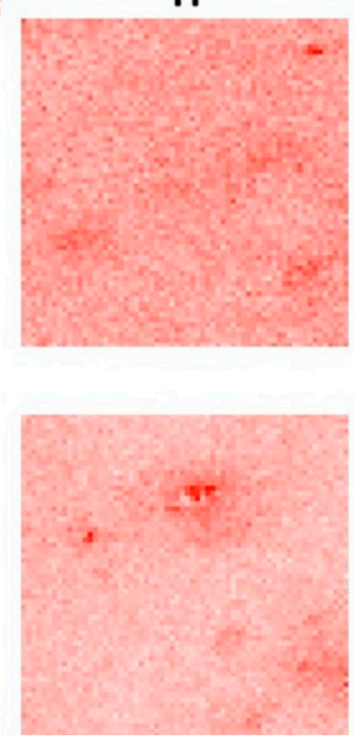

$\mathrm{Ni}$
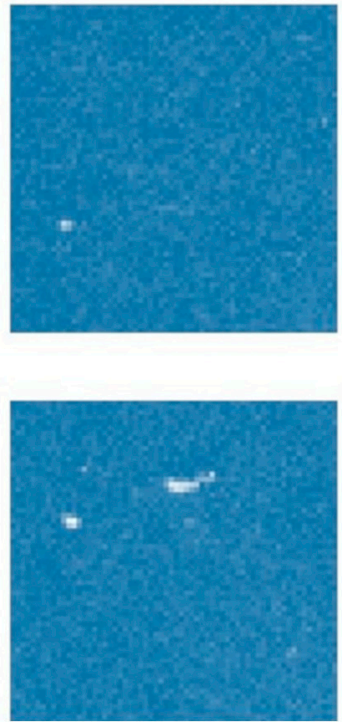
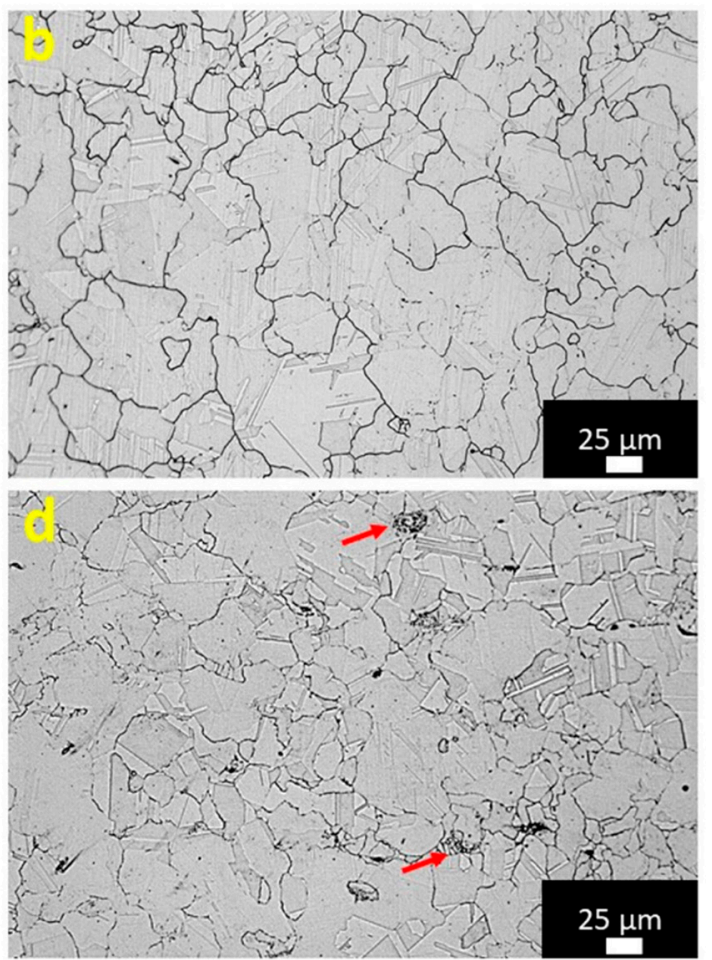

$\mathrm{Cr}$
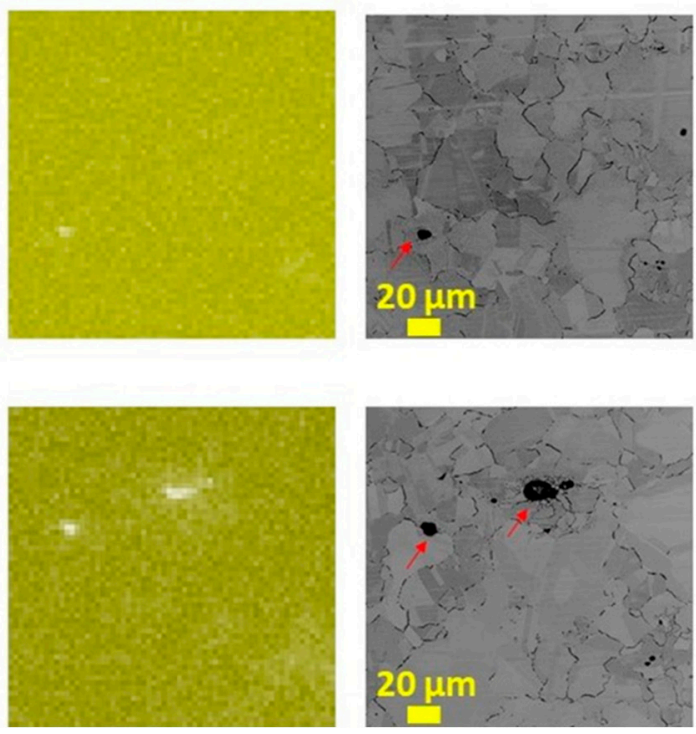

Figure 5. LOM images of the ST IN625 (a), STA IN625 (b), ST IN625mod (c), and STA IN625mod (d). Presence of residual Ti segregations (pointed by the red arrows). EDS maps of the STA IN625mod (e) showing the zones with Ti segregations with near-circular shape.

After aging treatment, the IN625 material revealed the formation of fine nanometric precipitates and a significant presence of sub-micrometric intergranular precipitates (Figure 6e,f). Likewise, precipitates could be detected for its modified version (Figure 6g,h). These precipitates can be $\gamma^{\prime \prime}$ phases for IN625 alloy and $\gamma^{\prime \prime}$ and $\gamma^{\prime}$ phases for the IN625mod version. It is reported that the addition of Ti in Inconel alloys can result in the formation of $\gamma^{\prime}$ phases while it can also favor the formation of $\gamma^{\prime \prime}$ phases for IN625 alloy [8]. Future studies will be performed to identify these phases. 

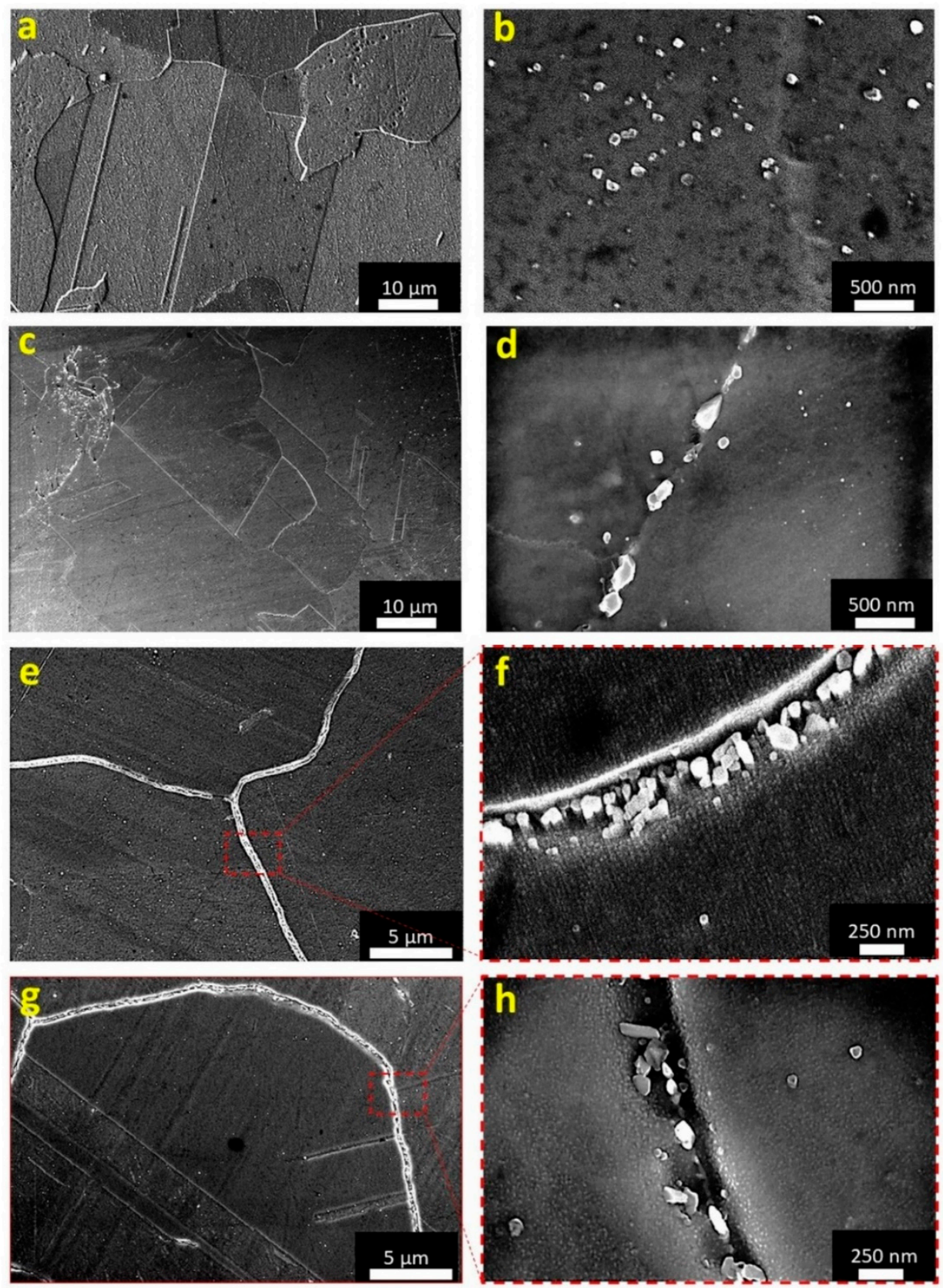

Figure 6. SEM images of the ST IN625 (a,b), ST IN625mod (c,d), STA IN625 (e,f), and STA IN625mod $(\mathbf{g}, \mathbf{h})$ showing the precipitates.

\subsection{Evolution of the Lattice Parameter of the Austenitic Phase}

Figure 7 displays the lattice parameter evolution of the austenitic phase for the two materials in the as-built and heat-treated conditions. Additionally, the XRD patterns of the peak (111) of the IN625 and IN625mod versions in the different conditions are given in Figure A3.

The AB state of the two conditions revealed similar lattice parameters, suggesting that the very high cooling rates of the process inhibited the complete assimilation of Ti-rich particles within the austenitic matrix. After solution treatment, the IN625mod version revealed broad lattice parameters than IN625 alloy due to the significant incorporation of the chemical elements of the Ti-rich microsegregations within the austenitic matrix alloy. The large lattice parameters also indicate that the formation of the clustering of carbides in the ST state was not so intense to induce a significant chemical element depletion to the lattice parameter of the austenitic matrix. Finally, a more marked reduction of 
the lattice parameters that occurred for the IN625mod version with respect to the IN625 alloy underwent aging treatments. This result can be associated with a more prominent formation of precipitates, provoking more chemical element depletion for the modified alloy than the base alloy under aging treatment. For IN625, similar variations of the lattice parameter of the austenitic matrix under heat treatment are also provided in other studies $[39,40]$.

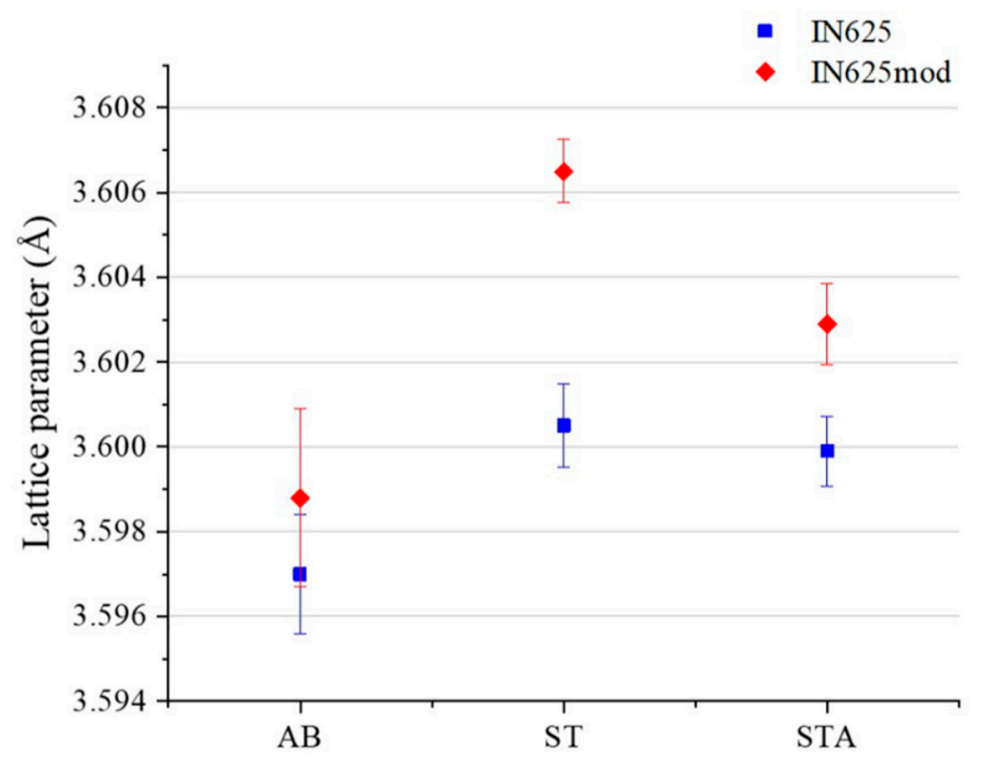

Figure 7. Lattice parameter of the austenitic matrix of the AB and heat-treated IN625 and IN625mod versions.

\subsection{Mechanical Properties and Fracture Surface Analysis}

The tensile properties and hardness of the two materials are given in Figure 8, while the tensile stress-strain curves of the IN625 and IN625mod conditions are displayed in Figure A4 (Appendix A).

The yield strength (YS) and ultimate tensile strength (UTS), elongation at failure, and hardness are similar for the AB state of the two materials. For the ST state, the IN625mod version presented higher YS (around 10\%), UTS (around 4\%), and hardness (around 6\%) with comparable elongation at failure with respect to the base alloy. This can be mainly attributed to the solution strengthening effect of the addition of Ti within the alloy. Moreover, the formation of a higher concentration of precipitates close to the segregated areas could also help to increase the tensile strengths. Finally, for the STA state, the IN625mod version presented higher YS (around 26\%), UTS (around 13\%), and hardness (around 15\%), but lower ductility (around 28\%), than the STA IN625 condition due to the more intense formation of precipitates generated during the aging treatment. This evidences the enhanced precipitation strengthening of the modified alloy.

Figure 9 reports the fracture surface for the different conditions of IN625 and IN625mod versions. The fracture surfaces revealed both ductile and brittle fractures. The AB and ST states exhibited similar characteristics with the formation of microvoids generated during the deformation. On the other hand, the STA IN625mod version exhibited more brittle fractures than the STA IN625 alloy due to the formation of a large number of strengthening phases, thus impacting its ductility, as highlighted by the results of the tensile test. Especially, the intergranular phases could play a crucial role in the formation of brittle fractures for the STA states. 


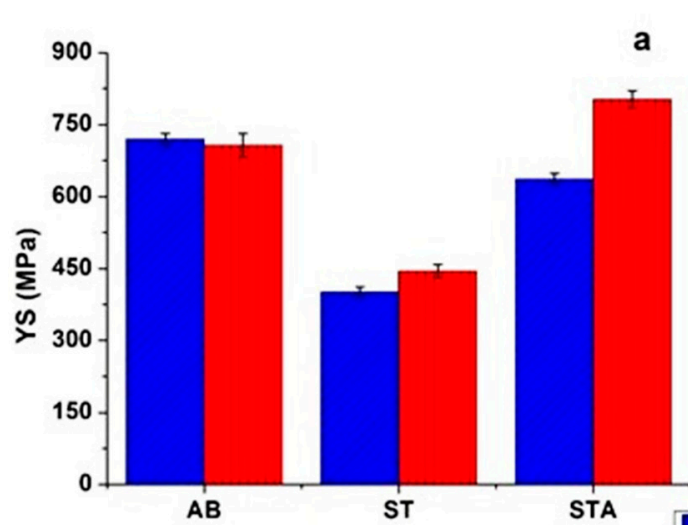

a

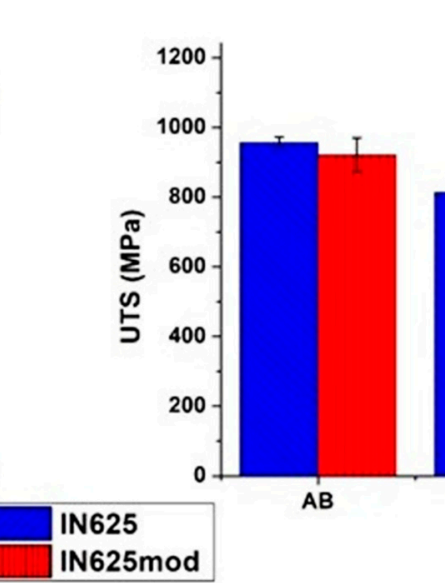

C

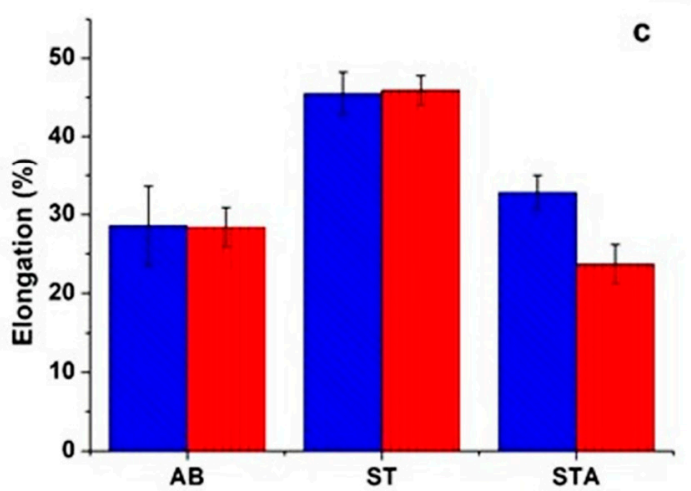

b

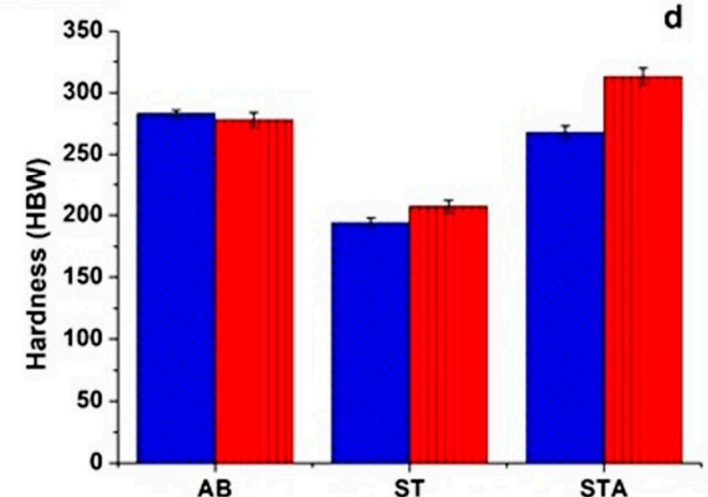

Figure 8. Mechanical properties of the IN625 and IN625mod in the different conditions: YS (a), UTS (b), elongation at failure (c), and Brinell hardness (d).
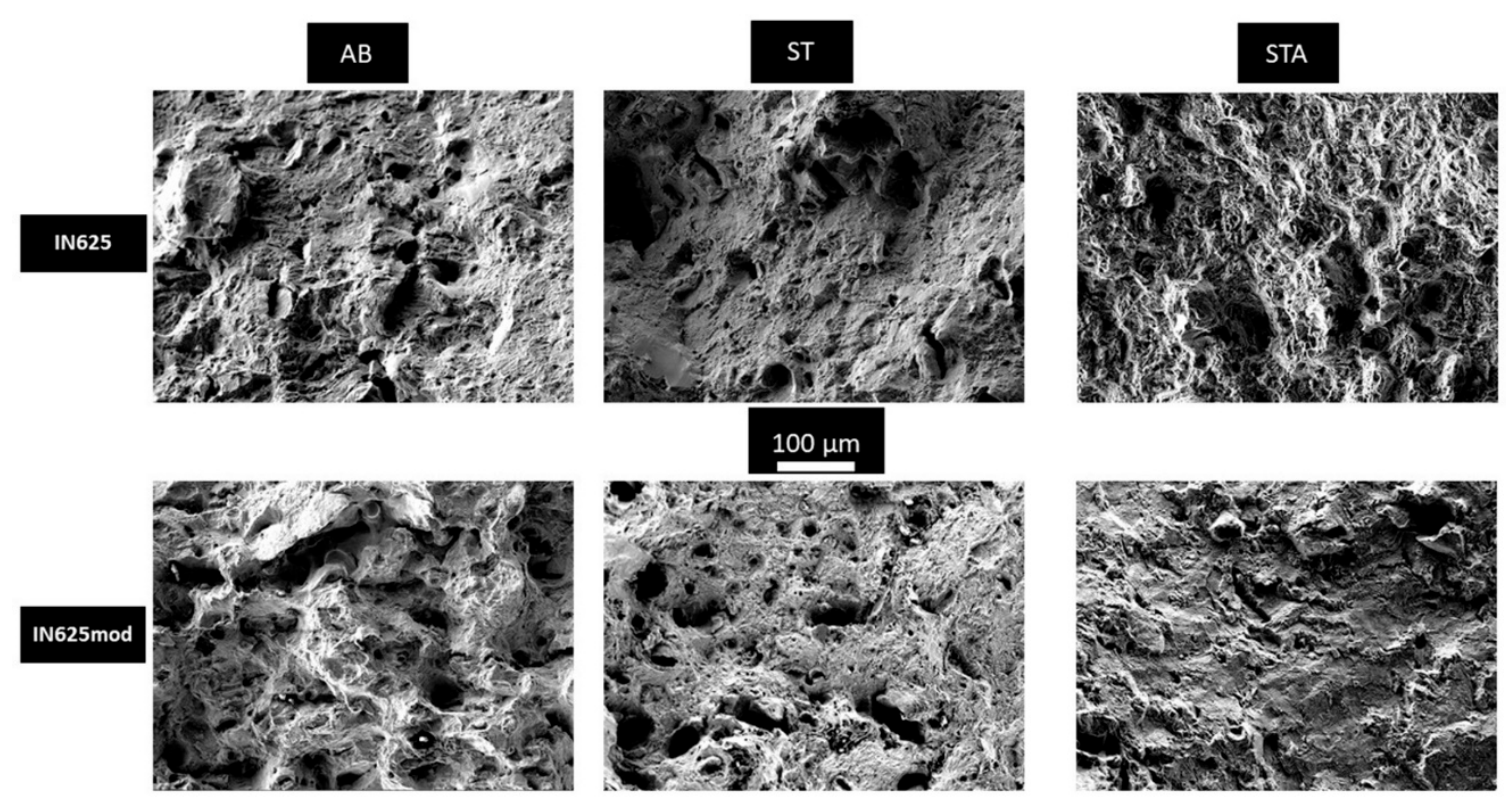

Figure 9. SEM images of the fracture surfaces of the IN625 and IN625mod in the different conditions.

\section{Discussion}

The IN625mod version presented densification similar to the IN625 with residual porosity $<0.2 \%$ when processed by LPBF. In the as-built version, the IN625mod material exhibited Ti-rich segregation areas chiefly located along the melt pool contours. The LPBF process involves extremely high solidification rates that avoid a complete chemical element 
diffusion of the Ti-rich particles necessary to reach a full homogenization. More in detail, Ti tends to segregate to the interdendritic areas during the solidification, reducing the quantity of Ti assimilated within the austenitic matrix [41-43]. The limited dissolution of Ti was also clearly pointed out by the lattice parameter of the austenitic matrix of AB IN625mod determined by XRD analysis, which resulted very close to the standard AB IN625.

However, the solution annealing treatment at high temperature $\left(1150{ }^{\circ} \mathrm{C}\right.$ for $\left.2 \mathrm{~h}\right)$ completely suppressed the interdendritic structures with the entrapped Ti. Consequently, Ti was assimilated as a solute element into the austenitic matrix, thus increasing its lattice parameter. Moreover, the heat treatment allowed activating the recrystallization and grain growth.

SEM + EDS analyses showed a good dispersion of the Ti, except for a few segregate areas along the melt pool contours. The solute strengthening effect of Ti resulted in increasing both hardness and tensile strengths with respect to the IN625 alloy without apparently producing a detectable impact on the ductility. However, the presence of clustering of precipitates close to the Ti-rich segregation areas should be noted. These segregations could be reduced in the as-built state, increasing the energy delivered to the material during the LPBF process, even though too high energy could create melt pool instability, thus triggering the formation of more pores. For the in situ chemical alloying, it is therefore essential to check the parameters to avoid the melt pool instability and reduce the segregation zones.

Even if the segregations might be entirely suppressed by tailoring the process parameters (like the application of a more powerful laser beam), the solution annealing treatment is essential to bring into the austenitic matrix the high quantity of Ti entrapped into the interdendritic areas during the solidification. After the solution annealing, the microstructure consisted of equiaxed grains with annealing twin grain boundaries. Submicrometric carbides can form under similar thermal exposures. For the ST IN625mod, the enrichment of Ti can favor more precipitation of carbides like MC type in segregate areas, also impacting the mechanical properties.

Under the current aging treatment $\left(700^{\circ} \mathrm{C}\right.$ for $\left.8 \mathrm{~h}\right)$, IN625 alloy was subjected to the formation of $\gamma^{\prime \prime}$ phases and carbides [8]. Moreover, the addition of Ti could promote the formation of $\gamma^{\prime}$, as reported in the literature for alloys deriving from IN625 modifications (e.g., custom age 625 plus and Inconel 725) with an enhanced content of Ti. Actually, Ti is one of the forming chemical elements of the $\gamma^{\prime}$ phase, and alloys derived from IN625 like Inconel 725 with higher Ti content are typically subjected to its formation. For Nibased superalloys, the formation of a higher quantity of strengthening phases produced a reduction of the lattice parameters of the austenitic matrix. In the current study, this is evident by comparing the lattice parameter variation of the IN625 alloy and IN625mod versions from the solution annealed to the aged conditions.

The mechanical properties of the AB IN625mod presented mechanical properties similar to AB IN625 alloy due to the limited assimilation of Ti within the austenitic matrix. However, it is interesting to note that the ST IN625mod version was characterized by higher YS and UTS and similar elongation compared to the ST IN625 alloy, mainly due to the solution strengthening effect. This also confirms that the clustering of carbides in some areas had a neglectable impact on the ductility since the two conditions exhibited similar elongation at failure. On the other hand, for the aged condition, the STA IN625mod version revealed higher YS and UTS associated with a major ductility degradation than STA IN625 alloy. This can be attributed to more intense precipitation of phases under the aging treatment.

Likewise, traditional alloy custom age 625 plus presents superior precipitation strengthening ability than IN625 alloy, generating higher tensile strengths and faster ductility reduction under shorter aging treatments with respect to the IN625 alloy [24]. The potential aspects of alloys such as Inconel 725 and custom age 625 plus are the possibility to obtain superior mechanical properties than Inconel 625 combined with similar corrosion protection $[9,24,27]$. 
The addition of only $1 \mathrm{wt} . \%$ of Ti-rich particles within IN625 alloy using appropriate process parameters and subsequent heat treatments presented attractive results on the microstructure and mechanical properties evolution. Nevertheless, the negative aspects remained the presence of segregation areas, which could not be eliminated by subsequent heat treatments. This aspect could be further investigated using LPBF machines with a more powerful laser beam or adding finer Ti powder for the mixing in order to improve and further explore the alloy development for the AM field.

\section{Conclusions}

This study contributes to investigate the alloy development by means of the in situ alloying of a Ni-based superalloy by LPBF. A similar approach can be useful to investigate possible new chemical compositions, thus reducing the high cost of gas atomized powder with a tailored chemical composition.

The addition of Ti6Al4V powder within IN625 was performed in order to evaluate the potential and limitations of the in situ alloying by the LPBF process. The modified IN625 version presented greater precipitation strengthening ability under aging treatment with respect to the standard IN625 alloy.

The current study revealed that Ti-rich segregations remained mainly within the melt pool contours in the as-built state. The LPBF process is actually rapid, and the melt pools solidify very rapidly, avoiding a complete Ti diffusion within the matrix. For these reasons, Ti remained mainly trapped along the melt pool contours and inside the interdendritic areas, thus not allowing it to reach a full homogenization. A subsequent solution annealing treatment eliminated the smaller Ti-rich segregation inside the interdendritic areas, contributing to homogenize the material, even though the coarse segregations remained.

The impact of the in situ alloying on IN625 through LPBF on the microstructure and mechanical properties was studied, and the main results can be hereafter summarized:

- Densification level similar to the base alloy when processed by LPBF with a residual porosity $<0.2 \%$;

- The as-built conditions revealed segregations within the melt pool contours (dimensions mainly around $20 \mu \mathrm{m}$ with a concentration of around $0.30 \%$ ). Additionally, Ti was also segregated into the interdendritic areas. Excluding the presence of a few Ti-rich segregations in the AB IN625mod, the microstructure of the modified version was similar to the AB IN625, and consequently, the mechanical properties also resulted to be in the same range.

- The solution treatment suppressed the interdendritic structures, thus allowing the Ti to be incorporated within the austenitic matrix, producing solute strengthening reinforcement. The tensile properties of the ST IN625mod version presented slightly higher YS and UTS but similar elongation at failure than ST IN625 alloy.

- For the IN625mod version, the subsequent aging treatment produced a more significant formation of precipitates with respect to the IN625 alloy. For this reason, the STA IN625mod version exhibited higher YS, UTS, and lower elongation at failure than STA IN625 alloy.

This study drives the attention to the possibility of combining commonly used powders by means of LPBF, generating new Ni-based superalloys tailored to enhance specific properties such as the precipitation strengthening ability under heat treatments.

Author Contributions: Conceptualization, G.M.; methodology, G.M. and A.A.; investigation, G.M., M.B. and A.A.; resources, S.B.; data curation, G.M. and M.B.; writing-original draft preparation, G.M. and M.B.; writing-review and editing, G.M., M.B., A.A. and S.B.; supervision, G.M. and S.B.; All authors have read and agreed to the published version of the manuscript.

Funding: This research received no external funding.

Data Availability Statement: The data presented in this study are available upon reasonable request from the corresponding author. 
Acknowledgments: The authors would like to acknowledge Simone Parizia for contributing to the metallographic preparation. Moreover, the authors would like to acknowledge the Integrated Additive Manufacturing Centre at Politecnico di Torino (IAM@PoliTo), where the specimens were produced.

Conflicts of Interest: The authors declare no conflict of interest.

\section{Appendix A}

The tensile specimens were fabricated with the final shapes by means of the LPBF process, as displayed in Figure A1. These dimensions are inside the ASTM E8/E8M21 standard.

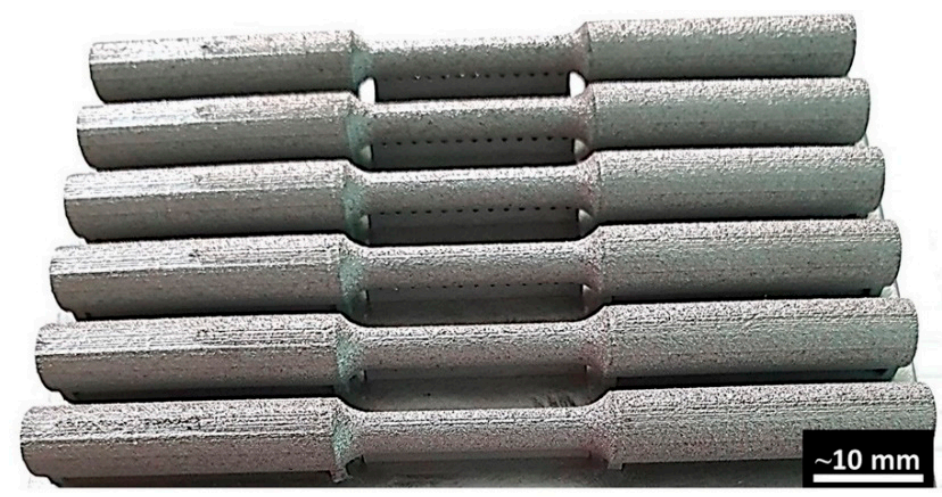

Figure A1. Image of some produced tensile specimens on the building platform of $90 \times 90 \mathrm{~mm}^{2}$.

For the AB IN625mod state, Figure A2 shows the method used to estimate the concentration of segregations using post-processing by means of ImageJ software. Twenty LOM images obtained at a magnification of $200 \times$ were analyzed.

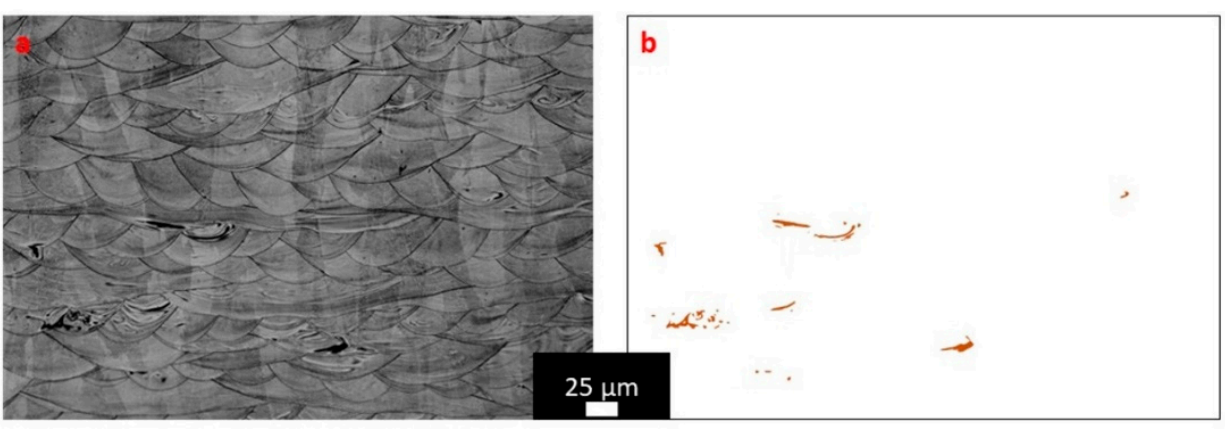

Figure A2. LOM images of AB IN625mod version after etching (a) and post-processed (b) to highlight the Ti-rich segregations.

The XRD patterns of the peak (111) of the IN625 and IN625mod versions in the different conditions are provided in Figure A3a,b, respectively. It is possible to observe the variation of the peak under heat treatments. After solution annealing, chemical elements are incorporated into the austenitic matrix, thus increasing its lattice parameter with respect to the $\mathrm{AB}$ state (and consequently the peak shift at a lower value of 2 theta). On the other hand, the formation of phases under aging treatment (STA condition) involves a reduction of the lattice parameter of the austenitic phase with respect to the ST state (and consequently the peak shift at a higher value of 2 theta). 

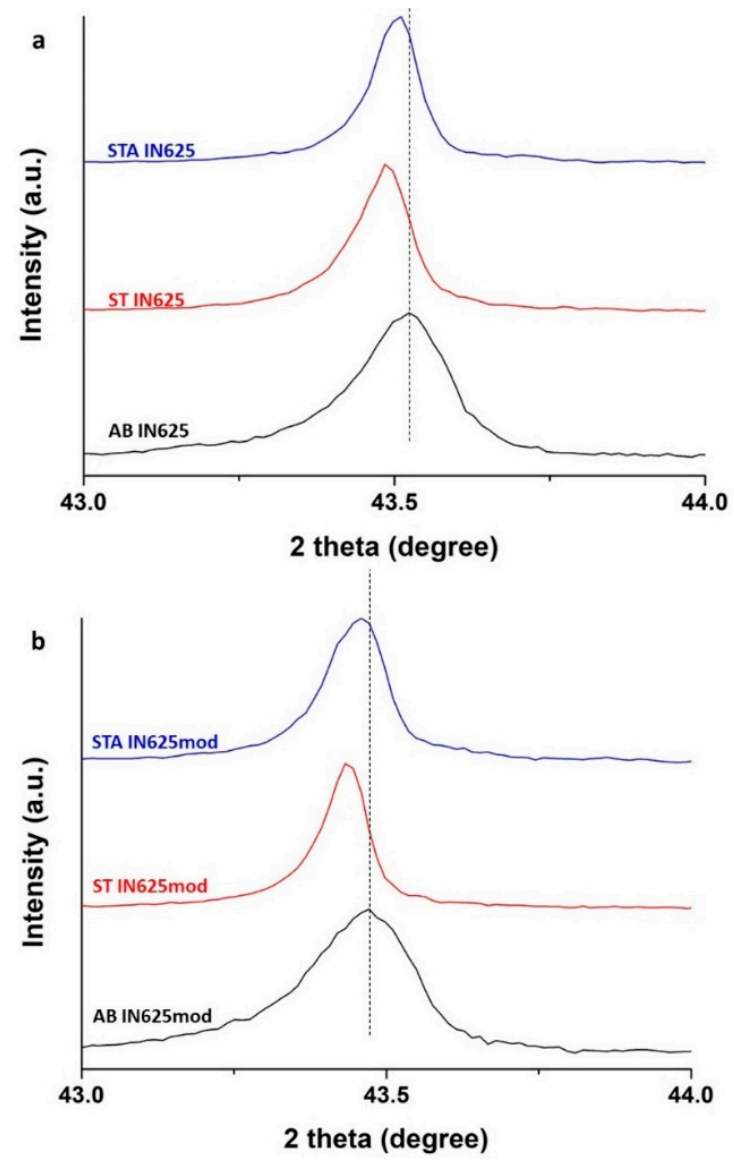

Figure A3. XRD patterns of the peak (111) of the (a) IN625 and (b) IN625mod in the AB, ST, and STA conditions.

For IN625 and IN625mod, a representative tensile curve of each condition is given in Figure A4.

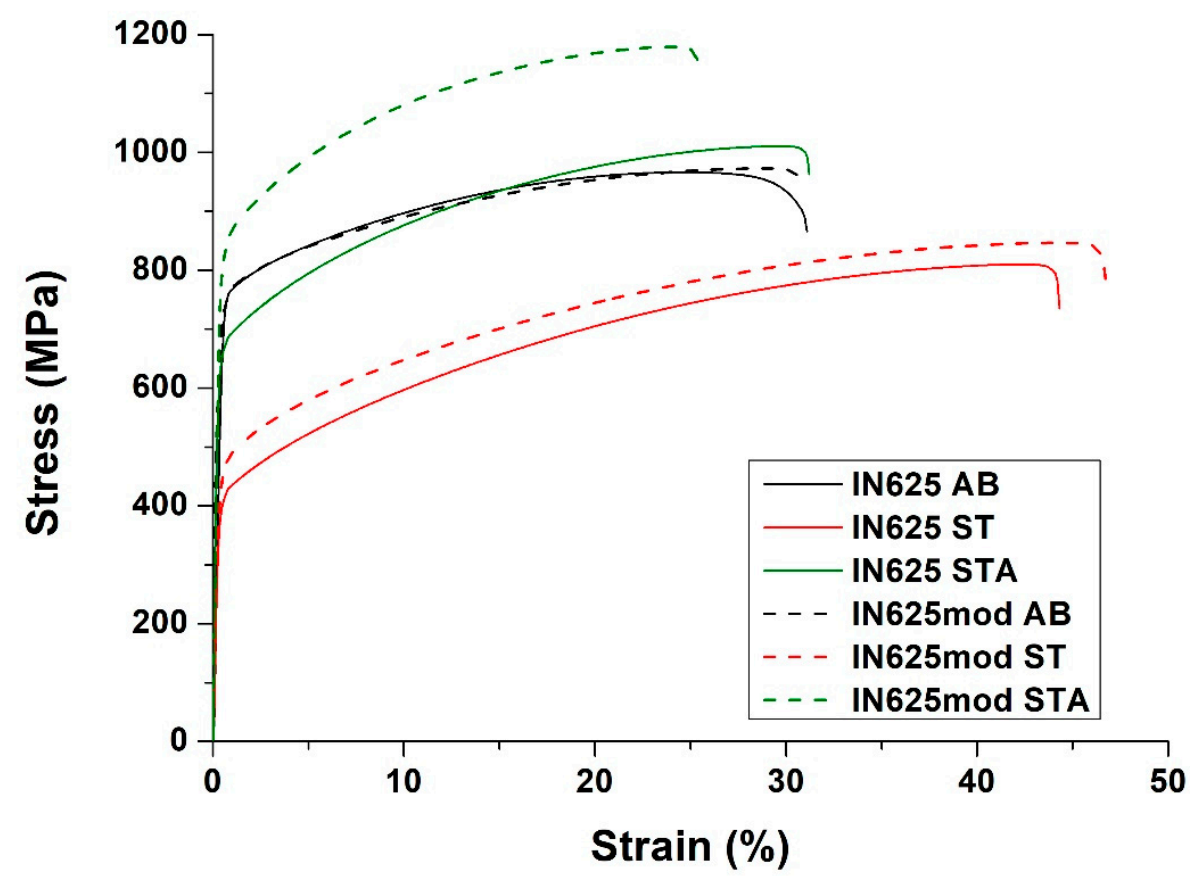

Figure A4. Representative plots of the tensile stress-strain curves of the IN625 and IN625mod conditions. 


\section{References}

1. Gu, D.D.; Meiners, W.; Wissenbach, K.; Poprawe, R. Laser additive manufacturing of metallic components: Materials, processes and mechanisms. Int. Mater. Rev. 2012, 57, 133-164. [CrossRef]

2. Herderick, E. Additive manufacturing of metals: A review. Mater. Sci. Technol. 2011, 2, 1413-1425.

3. DebRoy, T.; Wei, H.L.; Zuback, J.S.; Mukherjee, T.; Elmer, J.W.; Milewski, J.O.; Beese, A.M.; Wilson-Heid, A.; De, A.; Zhang, W. Additive manufacturing of metallic components-Process, structure and properties. Prog. Mater. Sci. 2018, 92, 112-224. [CrossRef]

4. Herzog, D.; Seyda, V.; Wycisk, E.; Emmelmann, C. Additive manufacturing of metals. Acta Mater. 2016, 117, 371-392. [CrossRef]

5. Carter, L.N.; Wang, X.; Read, N.; Khan, R.; Aristizabal, M.; Essa, K.; Attallah, M.M. Process optimisation of selective laser melting using energy density model for nickel based superalloys. Mater. Sci. Technol. 2016, 32, 657-661. [CrossRef]

6. Read, N.; Wang, W.; Essa, K.; Attallah, M.M. Selective laser melting of AlSi10Mg alloy: Process optimisation and mechanical properties development. Mater. Des. 2015, 65, 417-424. [CrossRef]

7. Shamsaei, N.; Yadollahi, A.; Bian, L.; Thompson, S.M. An overview of Direct Laser Deposition for additive manufacturing; Part II: Mechanical behavior, process parameter optimization and control. Addit. Manuf. 2015, 8, 12-35. [CrossRef]

8. Floreen, S.; Fuchs, G.E.; Yang, W.J. The Metallurgy of Alloy 625. In Superalloys 718, 625, 706 and Various Derivatives; Loria, E.A., Ed.; The Minerals, Metals \& Materials Society: Pittsburgh, PA, USA, 1994; pp. 13-37.

9. Shoemaker, L.E. Alloys 625 and 725: Trends in properties and applications. In Superalloys 718, 625, 706 and Derivatives; Loria, E.A., Ed.; The Minerals, Metals \& Materials Society: Pittsburgh, PA, USA, 2005; pp. 409-418.

10. Eiselstein, H.; Tillack, D. The Invention and Definition of Alloy 625. In Superalloys 718, 625 and Various Derivatives; Loria, E.A., Ed.; The Minerals, Metals \& Materials Society: Pittsburgh, PA, USA, 1991; pp. 1-14.

11. Cabrini, M.; Lorenzi, S.; Testa, C.; Brevi, F.; Biamino, S.; Fino, P.; Manfredi, D.; Marchese, G.; Calignano, F.; Pastore, T. Microstructure and selective corrosion of alloy 625 obtained by means of laser powder bed fusion. Materials 2019, $12,1742$. [CrossRef]

12. Tian, Z.; Zhang, C.; Wang, D.; Liu, W.; Fang, X.; Wellmann, D.; Zhao, Y.; Tian, Y. A review on laser powder bed fusion of inconel 625 nickel-based alloy. Appl. Sci. 2020, 10, 81. [CrossRef]

13. Marchese, G.; Parizia, S.; Rashidi, M.; Saboori, A.; Manfredi, D.; Ugues, D.; Lombardi, M.; Hryha, E.; Biamino, S. The role of texturing and microstructure evolution on the tensile behavior of heat-treated Inconel 625 produced via laser powder bed fusion. Mater. Sci. Eng. A 2020, 769, 138500. [CrossRef]

14. Kreitcberg, A.; Brailovski, V.; Turenne, S. Effect of heat treatment and hot isostatic pressing on the microstructure and mechanical properties of Inconel 625 alloy processed by laser powder bed fusion. Mater. Sci. Eng. A 2017, 689, 1-10. [CrossRef]

15. Gokcekaya, O.; Ishimoto, T.; Hibino, S.; Yasutomi, J.; Narushima, T.; Nakano, T. Unique crystallographic texture formation in Inconel 718 by laser powder bed fusion and its effect on mechanical anisotropy. Acta Mater. 2021, 212, 116876. [CrossRef]

16. Popovich, V.A.; Borisov, E.V.; Popovich, A.A.; Sufiiarov, V.S.; Masaylo, D.V.; Alzina, L. Functionally graded Inconel 718 processed by additive manufacturing: Crystallographic texture, anisotropy of microstructure and mechanical properties. Mater. Des. 2017, 114, 441-449. [CrossRef]

17. Inaekyan, K.; Kreitcberg, A.; Turenne, S.; Brailovski, V. Microstructure and mechanical properties of laser powder bed-fused IN625 alloy. Mater. Sci. Eng. A 2019, 768, 138481. [CrossRef]

18. Marchese, G.; Bassini, E.; Parizia, S.; Manfredi, D.; Ugues, D.; Lombardi, M.; Fino, P.; Biamino, S. Role of the chemical homogenization on the microstructural and mechanical evolution of prolonged heat-treated laser powder bed fused Inconel 625 . Mater. Sci. Eng. A 2020, 796, 140007. [CrossRef]

19. Bahador, A.; Umeda, J.; Yamanoglu, R.; Ghandvar, H.; Issariyapat, A.; Abu Bakar, T.A.; Kondoh, K. Deformation mechanism and enhanced properties of $\mathrm{Cu}-\mathrm{TiB} 2$ composites evaluated by the in-situ tensile test and microstructure characterization. J. Alloys Compd. 2020, 847, 156555. [CrossRef]

20. Shi, Q.; Gu, D.; Xia, M.; Cao, S.; Rong, T. Effects of laser processing parameters on thermal behavior and melting/solidification mechanism during selective laser melting of TiC/Inconel 718 composites. Opt. Laser Technol. 2016, 84, 9-22. [CrossRef]

21. Wang, P.; Zhang, B.; Tan, C.C.; Raghavan, S.; Lim, Y.F.; Sun, C.N.; Wei, J.; Chi, D. Microstructural characteristics and mechanical properties of carbon nanotube reinforced Inconel 625 parts fabricated by selective laser melting. Mater. Des. 2016, 112, 290-299. [CrossRef]

22. Chen, L.; Sun, Y.; Li, L.; Ren, X. Microstructure evolution, mechanical properties, and strengthening mechanism of TiC reinforced Inconel 625 nanocomposites fabricated by selective laser melting. Mater. Sci. Eng. A 2020, 792, 139655. [CrossRef]

23. Zhang, B.; Bi, G.; Nai, S.; Sun, C.N.; Wei, J. Microhardness and microstructure evolution of TiB2 reinforced Inconel 625/TiB2 composite produced by selective laser melting. Opt. Laser Technol. 2016, 80, 186-195. [CrossRef]

24. Schmidt, N.B.; DeBold, T.A.; Frank, R.B. Custom age $625^{\circledR}$ plus alloy-A higher strength alternative to alloy 625. J. Mater. Eng. Perform. 1992, 1, 483-488. [CrossRef]

25. Voort, G.F.V.; Bowman, J.W.; Frank, R.B. Microstructural Characterization of Custom Age 625 Plus Alloy. In Superalloys 718, 625, 706 and Derivatives; Loria, E.A., Ed.; The Minerals, Metals \& Materials Society: Pittsburgh, PA, USA, 1994; pp. $489-498$.

26. Frank, R.B.; Grimes, R. Properties of Ultra-High-Strength Custom Age 625 Plus Alloy. In Superalloys 718, 625, 706 and Various Derivatives; Loria, E.A., Ed.; The Minerals, Metals \& Materials Society: Pittsburgh, PA, USA, 1994; pp. 499-508. 
27. Hibner, E.L.; Sizek, H.W.; Mannan, S.K. Elevated Temperature Tensile and Creep Rupture Properties of INCONEL alloy 725. In Superalloys 718, 625, 706 and Various Derivatives; Loria, E.A., Ed.; The Minerals, Metals \& Materials Society: Pittsburgh, PA, USA, 1997; pp. 491-501.

28. Attallah, M.M.; Jennings, R.; Wang, X.; Carter, L.N. Additive manufacturing of Ni-based superalloys: The outstanding issues. MRS Bull. 2016, 41, 758-764. [CrossRef]

29. Carter, L.N.; Martin, C.; Withers, P.J.; Attallah, M.M. The influence of the laser scan strategy on grain structure and cracking behaviour in SLM powder-bed fabricated nickel superalloy. J. Alloys Compd. 2014, 615, 338-347. [CrossRef]

30. Zhang, X.; Chen, H.; Xu, L.; Xu, J.; Ren, X.; Chen, X. Cracking mechanism and susceptibility of laser melting deposited Inconel 738 superalloy. Mater. Des. 2019, 183, 108105. [CrossRef]

31. Vilardell, A.M.; Yadroitsev, I.; Yadroitsava, I.; Albu, M.; Takata, N.; Kobashi, M.; Krakhmalev, P.; Kouprianoff, D.; Kothleitner, G.; $\mathrm{du}$ Plessis, A. Manufacturing and characterization of in-situ alloyed Ti6Al4V(ELI)-3 at.\% Cu by laser powder bed fusion. Addit. Manuf. 2020, 36, 101436. [CrossRef]

32. Mosallanejad, M.H.; Niroumand, B.; Aversa, A.; Manfredi, D.; Saboori, A. Laser Powder Bed Fusion in-situ alloying of Ti-5\%Cu alloy: Process-structure relationships. J. Alloys Compd. 2020, 857, 157558. [CrossRef]

33. Vrancken, B.; Thijs, L.; Kruth, J.P.; Van Humbeeck, J. Microstructure and mechanical properties of a novel $\beta$ titanium metallic composite by selective laser melting. Acta Mater. 2014, 68, 150-158. [CrossRef]

34. Simonelli, M.; Aboulkhair, N.T.; Cohen, P.; Murray, J.W.; Clare, A.T.; Tuck, C.; Hague, R.J.M. A comparison of Ti-6Al-4V in-situ alloying in Selective Laser Melting using simply-mixed and satellited powder blend feedstocks. Mater. Charact. 2018, 143, 118-126. [CrossRef]

35. Chandler, H. Heat Treater's Guide: Practices and Procedures for Nonferrous Alloys; ASM International: Materials Park, OH, USA, 1996; ISBN 0871705656.

36. Nelson, J.B.; Riley, D.P. An experimental investigation of extrapolation methods in the derivation of accurate unit-cell dimensions of crystals. Proc. Phys. Soc. 1945, 57, 160. [CrossRef]

37. Parizia, S.; Marchese, G.; Rashidi, M.; Lorusso, M.; Hryha, E.; Manfredi, D.; Biamino, S. Effect of heat treatment on microstructure and oxidation properties of Inconel 625 processed by LPBF. J. Alloys Compd. 2020, 846, 156418. [CrossRef]

38. Cortial, F.; Corrieu, J.M.; Vernot-Loier, C. Influence of heat treatments on microstructure, mechanical properties, and corrosion resistance of weld alloy 625. Metall. Mater. Trans. A 1995, 26, 1273-1286. [CrossRef]

39. Kreitcberg, A.; Brailovski, V.; Turenne, S. Elevated temperature mechanical behavior of IN625 alloy processed by laser powder-bed fusion. Mater. Sci. Eng. A 2017, 700, 540-553. [CrossRef]

40. Rai, S.K.; Kumar, A.; Shankar, V.; Jayakumar, T.; Rao, K.B.S.; Raj, B. Characterization of microstructures in Inconel 625 using X-ray diffraction peak broadening and lattice parameter measurements. Scr. Mater. 2004, 51, 59-63. [CrossRef]

41. Griffiths, S.; Ghasemi Tabasi, H.; Ivas, T.; Maeder, X.; De Luca, A.; Zweiacker, K.; Wróbel, R.; Jhabvala, J.; Logé, R.E.; Leinenbach, C. Combining alloy and process modification for micro-crack mitigation in an additively manufactured Ni-base superalloy. Addit. Manuf. 2020, 36. [CrossRef]

42. Zhang, J. Effect of Ti and Ta on hot cracking susceptibility of directionally solidified Ni-based superalloy IN792. Scr. Mater. 2003, 48, 677-681. [CrossRef]

43. D'Souza, N.; Dong, H.B. Solidification path in third-generation Ni-based superalloys, with an emphasis on last stage solidification. Scr. Mater. 2007, 56, 41-44. [CrossRef] 